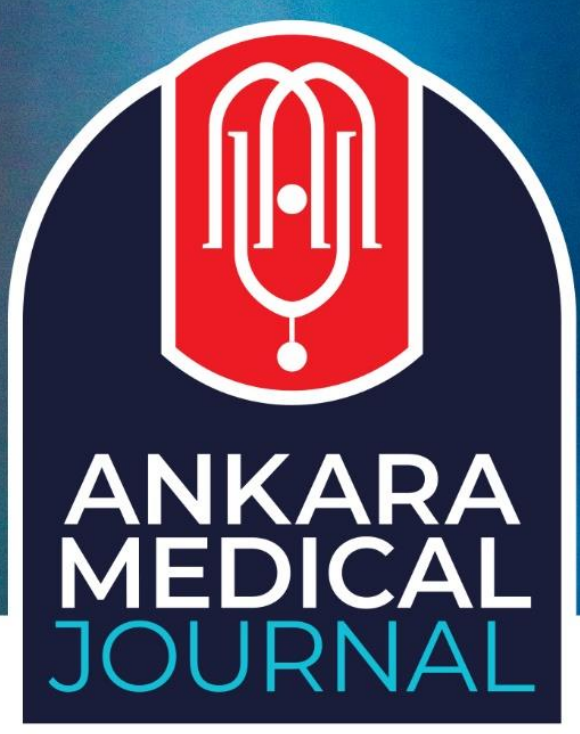

Araștırma Makalesi

Ankara Med J, 2020;(4):1027-1040 // (0) 10.5505/amj.2020.24654

UYGUNSUZ İLAÇ KULLANIMI AÇISINDAN 2015 VE 2019 AGS BEERS KRITERLERİ ARASINDA KLİNIK OLARAK ANLAMLI FARK VAR MI: KESITTSEL BİR ÇALIŞMA

\title{
IS THERE A SIGNIFICANT CLINICAL DIFFERENCE BETWEEN 2015 AND 2019 AGS BEERS CRITERIA IN TERMS OF INAPPROPRIATE DRUG USE: A CROSS- SECTIONAL STUDY
}

(D) Şuayip Enes Arslan1, (D) Basri Furkan Dağcıoğlu1

${ }^{1}$ Ankara Yıldırım Beyazıt Üniversitesi Tıp Fakültesi, Aile Hekimliği AD.

Yazışma Adresi / Correspondence:

Dr. Öğr. Üyesi Basri Furkan Dağcığlu (e-posta: bfurkan@gmail.com)

Geliş Tarihi: 13.11.2020 // Kabul Tarihi: 26.11.2020

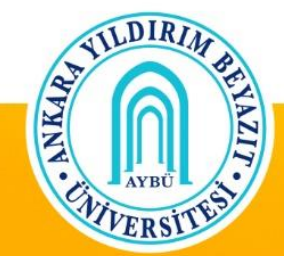

Ankara Yildırım Beyazıt University Faculty of Medicine Department of Family Medicine 


\title{
Öz
}

Amaç: Evde Sağlık Birimi'ne kayıtlı 65 yaş ve üstü hastalarda çoklu ilaç kullanımının tespit edilmesi, ilaçların 2015 ve 2019 AGS Beers Kriterleri kriterlerine göre uygun olup olmadığının belirlenmesi, iki versiyon arasında klinik açıdan anlamlı farklılık olup olmadığının araştırılması amaçlanmıştır.

Materyal ve Metot: Retrospektif tanımlayıcı tarzdaki çalışmamızda, kayıtlı 659 hasta dosyası tarandı. Verilerine ulaşılan 493 hastanın ilaç kullanım verileri 2015 ve 2019 AGS Beers kriterlerine göre analiz edildi. Bulgular: Çalışmaya 354'ü $(\% 71,81)$ kadın 493 hasta dahil edildi. Hastaların tanı almış hastalık sayısı ortancası 6 (min: 1, maks: 10) olup en sık görülen hastalıklar, hipertansiyon, yaygın anksiyete bozukluğu, diabetes mellitus idi. 490 hastanın kullandığı en az bir ilacı olup ilaç sayısı ortancası 7 (min: 0, maks: 16) idi. Hastaların 306 'sında $(\% 62,45)$ polifarmasi, 91'inde $(\% 18,57)$ aşırı polifarmasi saptandı. Potansiyel UíK durumu 2015 ve 2019 Beers kriterlerine göre 211 hastada saptandı. 2015 Beers Kriterlerine göre 358, 2019 Beers Kriterlerine göre 383 etken maddede uygunsuz ilaç kullanımı (UIK) belirlendi. Polifarmasi görülen hastalarda her iki versiyona göre de UíK sıklığı daha fazlaydı.

Sonuç: Polifarmasi saptanan hastalarda UİK durumunun da önemli oranda fazla olduğu görüldü. 2015 ve 2019 AGS Beers kriterlerinin UİK tespit durumu kıyaslandığında, 2019 versiyonunda daha fazla etken maddede uygunsuzluk saptandı.

Anahtar Kelimeler: Polifarmasi, Beers kriterleri, uygunsuz ilaç kullanımı, evde sağlık.

\begin{abstract}
Objectives: It is aimed to determine the use of multiple drugs in patients aged 65 and over who are registered in the Home Health Unit, to determine whether the drugs are suitable according to the 2015 and 2019 AGS Beers Criteria, and to investigate whether there is a clinically significant difference between the two versions. Materials and Methods: In our retrospective descriptive study, 659 patient files were scanned. The drug usage data of 493 patients, whose data were eligible, were analyzed according to the 2015 and 2019 AGS Beers criteria.

Results: The study included 493 patients, 354 (71.81\%) of whom were female. The median number of diagnosed diseases was 6 (min: 1, max: 10), and the most common diseases were hypertension, generalized anxiety disorder, and diabetes mellitus. At least one drug used by 490 patients and the median number of drugs was 7 (min: 0, max: 16). Polypharmacy was detected in 306 (62.45\%) patients and excessive polypharmacy in $91(18.57 \%)$ patients. Potential Inappropriate Medication (PIM) status was determined in 211 patients according to 2015 and 2019 Beers criteria. PIM status was determined in 358 active substances according to the 2015 Beers Criteria and 383 active substances according to the 2019 Beers Criteria. The frequency of PIM was higher in patients with polypharmacy compared to both versions.

Conclusion: PIM status was observed to be significantly higher in patients with polypharmacy. When the PIM detection status of the 2015 and 2019 AGS Beers criteria was compared, inappropriateness was found in more active ingredients in the 2019 version.
\end{abstract}

Keywords: Polypharmacy, Beers criteria, potential inappropriate medication, home health. 


\section{Giriş}

Yaşadığımız yüzyılın en önemli demografik olgusu nüfusun yaşlanmasıdır. Tüm dünyada doğum oranları azalmakta, ortalama ve beklenen yaşam süreleri artmakta ve bu nedenle yaşlı nüfusun sayısı ve oranı giderek artmaktadır. ${ }^{1}$ Yaşın ilerlemesiyle birlikte fizyolojik, bilişsel, psikolojik, emosyonel ve sosyal alanlarda değişiklikler oluşabilmekte, bireyin fonksiyonel kapasitesi azalmakla birlikte kronik hastalıklar artmaktadır. ${ }^{2}$ Bu durum yaşlılarda çoklu ilaç kullanımını beraberinde gerektirmektedir. Yapılan çalışmalar yaşlanma ile beraber reçete edilen ilaç sayısının da arttığını göstermektedir. ${ }^{3}$ Çoklu ilaç kullanımı; yan etki ve ilaçlar arası etkileşim riskinde, medikal tedaviye uyumsuzluk oranlarında, tedavi maliyetinde, hastaneye yatış gereksiniminde ve buna bağlı gelişen komorbid durumlarda artışa neden olmaktadır. ${ }^{4}$

Yaşlılarda çoklu ilaç kullanımı için polifarmasi ifadesi kullanılmakta olup en genel anlamıyla uygun endikasyonu olmaksızın en az bir ilacın kullanılması olarak tanımlanabilir. ${ }^{5}$ Bazı kaynaklara göre ise 5-9 arası ilaç kullanımı polifarmasi, 10 ve üzeri sayıda ilaç kullanımı ise aşırı polifarmasi olarak adlandırılmaktadır. ${ }^{6,7}$ Tüm dünyada olduğu gibi ülkemizde de çoklu ilaç kullanan sınıfın büyük kısmını 65 yaş ve üstü hastalar oluşturmaktadır. ${ }^{8}$

Uygunsuz ilaç kullanımı ise, herhangi bir ilacın endikasyon dışı veya yan etki açısından yüksek risk alınarak kullanımını ifade etmektedir. ${ }^{9}$ Polifarmaside, kullanılan ilaç sayısı arttıkça beraberinde uygunsuz ilaç kullanımı görülmektedir. Dolayısıyla, yaşlı hastalarda potansiyel olarak uygunsuz olabilecek ilaçların kullanımını belirlemek ve değerlendirmek önem arz etmektedir. Yaşlı hastalarda kullanımı riskli olabilecek ilaçları içeren, bu ilaçların kullanımını ve bu ilaçların kullanımına bağlı ortaya çıkabilecek problemleri azaltmak için uluslararası kabul görmüş çeşitli öneriler/kriterler yayınlanmıştır.10

Beers ve arkadaşları tarafından ilk kez tanımlanan Beers kriterleri, huzurevlerinde yaşayan yaşlıların kullandıkları ilaçların değerlendirilmesi amacıyla 1991 yılında yayınlanmıştır. Yaşlılarda olası uygunsuz ilaç kullanımı (UIK) durumunu önlemek amacıyla, 30 yıla yakın bir süredir kullanılmakta olan bu kriterler 2012 yılında Amerikan Geriatri Derneği [American Geriatric Society (AGS)] tarafından, 65 yaş ve üzeri yaşlıların kullandıkları ilaçların risklerinin, yararlarından daha fazla olduğunu tanımlamak amacıyla tekrar genişletilip güncellenmiştir. ${ }^{11,12}$ Sonrasında 2015 ve 2019 yıllarında tekrar güncellenen Beers kriterlerinin diğer bir amacl; olası uygunsuz ilaca maruziyeti azaltmak ve yaşlıların yaşam kalitesini artırmaktır.9,13

Bu çalışmada, Ankara Şehir Hastanesi Evde Sağlık Birimi'ne kayıtlı 65 yaş ve üstü hastalarda çoklu ilaç kullanımının tespit edilmesi, ilaçların 2015 AGS Beers Kriterleri ve 2019 AGS Beers kriterlerine göre uygun olup olmadığının belirlenmesi ve bu sayede iki versiyon arasında klinik açıdan anlamlı farklılıkların olup olmadığının araştırılması amaçlanmıştır. 


\section{Materyal ve Metot}

Kesitsel-tanımlayıcı yöntem kullanılan çalışmanın evrenini xxx Hastanesi Evde Sağlık Birimi'ne kayıtlı 65 yaş ve üstü tüm hastalar oluşturmaktaydı. Tüm hasta dosyaları incelenerek 01.09.2019 tarihi itibariyle hizmet verilen geriatrik hasta sayısının 659 olduğu belirlendi.

Dosyalarda hastalara ait cinsiyet, yaş, kullanılan ilaç sayısı, kullanılan ilaçların adları ve etken maddeleri, tanılı kronik hastalık sayısı gibi bilgiler oluşturulan kişisel veri toplama şablonuna kayıt edildi. Değerlendirmeye alınacak verilerin bulunmadığı hasta dosyaları kapsam dışında bırakıldı. Veriler 01.09.2019 - 01.11.2019 tarihleri arasında toplandı. Katılımcılardan bazıları vefat ve hasta dosyasındaki bilgilerin eksik olması gibi nedenlerle çalışma dışında bırakıldığından toplam 493 hastaya ait veriler analiz edildi. Yapılan güç analizinde $\% 2$ hata payıyla çalışmanın gücü \%95 olarak hesaplandı.

\section{AGS Beers kriterleri}

2011 yılından itibaren 3 yılda bir güncellenmesi planlanan ve son güncellemesi 2019 yllında yapılmış olan AGS Beers kriterlerinde; yaşlı hastalarda potansiyel uygunsuz ilaç kullanımı, ilaç-hastalık veya ilaç-sendrom etkileşimleri (hastalık veya sendromu alevlendirebilme riski) nedeniyle yaşlılarda kullanımı potansiyel uygunsuz ilaçlar, yaşlılarda dikkatli kullanılması gereken potansiyel uygunsuz ilaçlar, yaşlılarda kaçınılması gereken ilaç-ilaç etkileşimleri, kaçınılması gereken veya yaşlılarda böbrek fonksiyonlarına göre doz azaltılması gereken anti infektif olmayan ilaçlar şeklinde 5 bölüm bulunmaktadır. Her bölümde etken maddeler için gerekçe, öneri, kanıt kalitesi ve önerinin gücü belirtilmektedir. AGS Beers 2019 güncellemesinde bazı bölümlere etken maddeler eklenip çıkartılmış olup, bazı bölümlerdeki etken maddelerde ise gerekçe, öneri veya kanıt kalitesinde güncellemeler yapılmıștır. ${ }^{9}$ Çalışmamızda yaşlılarda dikkatli kullanılması gereken potansiyel uygunsuz ilaçlar (Bölüm 4) dışında kalan 4 bölüm kullanıldı. Bölüm-4'te yer alan ilaçların Bölüm-2 ve 3'e eklenecek kadar kilit unsur olarak görülmemesi gerektiği ve yarar-zarar dengesinde kullanılabilecek ilaçlar olduğunu belirtildiği için çalışmamızda kullanılmadı. ${ }^{13}$

\section{Verilerin analizi}

Toplanan veriler bilgisayar ortamına aktarıldı. İlk veri girişi için Microsoft Office Excel 2016 programı kullanıldı. Hastaların kullandıkları ilaçlar etken madde şeklinde girildikten sonra 2015 AGS Beers ve 2019 AGS Beers kriterleri kullanılarak, hasta bazında her bir kriter için potansiyel uygunsuz ilaç kullanımı durumları ve sayıları belirlendi. İstatistiksel değerlendirme için elde edilen veriler IBM SPSS Statistics 22 programına aktarıldı. Sürekli değişkenler (yaş, toplam kullanılan ilaç adedi, toplam hastalık sayısı vb) normal dağılıma bağlı olarak ortalama \pm standart sapma veya ortanca (min. - maks.) ile gösterildi. Kategorik değişkenlerin arasında 
bağımlılık incelenirken Pearson ki-kare ve Fisher's exact testi kullanıldı. İstatistiksel anlamlılık düzeyi p <0,05 olarak belirlendi.

\section{Bulgular}

Çalışmamıza dahil edilen hastaların 354'ünün (\%71,81) kadın olduğu, genel yaş ortalamasının 83,74 $\pm 7,68$ (min: 65, maks: 103) yll olduğu görüldü. Hastaların \%49,49’u(n=244) 85 yaş ve üzerindeyken, \%50,51'i (n=249) 85 yaş altındaydı. Katılımcıların cinsiyetlerine göre yaş ortalamaları incelendiğinde kadın hastaların yaş ortalamasının yüksek olduğu belirlenmiştir (Tablo 1).

Hastalıklar International Classification of Diseases 10th Revision'a (ICD-10) göre sınıflandırıldı. Çalışmamıza dahil edilen hastaların tanıları incelendiğinde 493 hastanın toplam 2243 kronik hastalık tanısı aldığı belirlendi. Hasta başına düşen tanı sayısı ortancası 6 (min:1, maks:10) olarak saptandı. Hastalık tanıları sistemlere göre ayrıldığında, 711 (\%31,70) dolaşım sistemi, 399 (\%17,79) endokrin, nutrisyon ve metabolik, 281 (\%12,53) sinir sistemi hastalıkları ve $227(\% 10,12)$ mental davranış bozuklukları tanı grubunda olduğu saptandı.

Hastaların aldıkları tanılar incelendiğinde, en sık tanılar arasında $361(\% 73,23)$ hipertansiyon, 163 (\%33,06) yaygın anksiyete bozukluğu, $140(\% 28,40)$ diabetes mellitus, $115(\% 23,33)$ Alzheimer ve 109 (\%22,11) aterosklerotik kalp hastalığı olduğu saptandı.

Çalışmamıza dahil edilen hastaların kullandıkları ilaçlar incelendiğinde ilaç kullanan 490 (\%99,39) hastanın, toplamda 3929 farklı ilaç kullandığı saptandı. Hastaların kullandıkları ilaç sayısı ortanca değeri 7 (min: 0, maks: 16), kullandıkları raporlu ilaç sayısı ortancası 5 (min: 0, maks: 15) olarak saptandı. Hastaların kullandıkları ilaçların sistemlere göre dağılımı incelendiğinde 1084 (\%27,59) ilacın sinir sistemi, 883 (\%22,47) ilacın kalp damar sistemi, $744(\% 18,94)$ ilacın sindirim sistemi ve metabolizma grubunda yer aldığı saptandı. Hastaların kullandıkları ilaçların etken maddelerin dağılımı incelendiğinde en sık kullanılan etken maddenin 175 $(\% 35,71)$ kişi ile asetilsalisilik asit olduğu ve tüm ilaçların \%4,45 ini oluşturduğu görüldü.

Hastaların kullandıkları ilaç sayısı ile hastalık sayısı incelendiğinde, 3 ve üstü hastalığı olan hastaların belirgin şekilde daha fazla ilaç kullandıkları görüldü (Tablo 2).

Hastaların uygunsuz ilaç kullanımları Beers kriterlerine göre değerlendirildi. Hem Beers 2015 hem de Beers 2019 kriterlerine göre UİK saptanan hastaların, uygunsuz kullandıkları ilaç durumu sayıları ortanca değeri 1 (min: 1, maks: 13) olarak saptandı. Bir ilacın en fazla üç bölümde uygunsuz ilaç kullanımı kriterlerini karşıladı̆̆ı görüldü. Beers alt kriterlerine göre hastaların uygunsuz ilaç kullanım durumları ve her bir alt kriterde en sık görülen üç uygunsuz ilaç Tablo 3 de gösterildi. 
Tablo 1. Hastaların yaş ortalamaları

\begin{tabular}{|l|l|c|c|c|c|c|c|}
\hline \multicolumn{2}{|l|}{} & n & Ortalama & $\begin{array}{c}\text { Standart } \\
\text { sapma }\end{array}$ & Minimum & Maksimum & p \\
\hline \multirow{2}{*}{ Cinsiyet } & Kadın & 354 & 84,43 & 7,829 & 66 & 103 & $0,002^{*}$ \\
\cline { 2 - 8 } & Erkek & 139 & 81,98 & 7,045 & 65 & 94 & 103 \\
\hline Genel & 493 & 83,74 & 7,68 & 65 & \\
\hline
\end{tabular}

*Mann Whitney-U

Tablo 2. Hastaların ilaç kullanım sayıları ile hastalık sayılarının karşılaştırılması

\begin{tabular}{|c|c|c|c|c|c|}
\hline \multirow[b]{2}{*}{ İlaç sayısı } & \multicolumn{3}{|c|}{ Kronik hastalık sayısı n(\%) } & \multirow[b]{2}{*}{$\mathbf{x}^{2}$} & \multirow[b]{2}{*}{$\mathbf{p}$} \\
\hline & $\begin{array}{c}\text { 3'ten az } \\
\text { n(\%) }\end{array}$ & $\begin{array}{c}3 \text { ve daha çok } \\
n(\%)\end{array}$ & $\begin{array}{c}\text { Toplam } \\
\text { n }\end{array}$ & & \\
\hline 1-4 arası & $46(49,46)$ & $47(50,54)$ & 93 & \multirow{3}{*}{133,352} & \multirow{3}{*}{$<0,001$} \\
\hline 5-9 arası & $7(2,29)$ & $299(97,71)$ & 306 & & \\
\hline 10 ve üstü & $1(1,10)$ & $90(98,90)$ & 91 & & \\
\hline
\end{tabular}

Uygunsuz ilaç kullanma sıklığının yaş gruplarına göre değişiklik göstermediği görüldü $\left(X^{2}=1,183 ; p=0,553\right)$. İlaç kullanan 490 hastanın en az bir uygunsuz ilaç kullanma durumları ile ilaç kullanma sayıları arasındaki ilişki incelendiğinde, ilaç kullanımı sayısı arttıkça uygunsuz ilaç kullanımın oranının da arttığı saptandı. UİK durumunun 1-4 arası ilaç kullanan hastalarda daha düşük, 10 ve üstü ilaç kullananlarda ise daha yüksek oranda olduğu saptandı (Tablo 4). 
Tablo 3. Hastaların Beers kriterleri bölümlerine göre uygunsuz ilaç kullanım sayıları ve her bölüme ait en sık saptanan uygunsuz ilaçlar

\begin{tabular}{|c|c|c|c|c|c|}
\hline \multirow{2}{*}{ Beers Kriterleri Bölümleri } & \multicolumn{2}{|c|}{ Beers 2015} & & \multicolumn{2}{|c|}{ Beers 2019} \\
\hline & $\mathbf{n}$ & $\%$ & & $\mathbf{n}$ & $\%$ \\
\hline $\begin{array}{l}\text { 1.Yaşlı Hastalarda } \\
\text { Potansiyel Uygunsuz İlaç } \\
\text { Kullanımı }\end{array}$ & 206 & 57,54 & & 206 & 53,79 \\
\hline \multicolumn{6}{|c|}{ En sık uygunsuzluk saptanan ilaçlar } \\
\hline Ketiapin & 70 & 19,55 & Ketiapin & 70 & 18,28 \\
\hline Doksazosin & 25 & 6,98 & Doksazosin & 25 & 6,53 \\
\hline Hidroksizin & 11 & 3,07 & Hidroksizin & 11 & 2,87 \\
\hline $\begin{array}{l}\text { 2. Hastalık veya Sendromu } \\
\text { Alevlendirme Riski } \\
\text { Nedeniyle Yaşlılarda } \\
\text { Kullanımı Uygunsuz İlaçlar } \\
\end{array}$ & 100 & 27,93 & & 100 & 26,11 \\
\hline \multicolumn{6}{|c|}{ En sık uygunsuzluk saptanan ilaçlar } \\
\hline Ketiapin & 42 & 11,73 & Ketiapin & 42 & 10,79 \\
\hline Asetilsalisilik asit & 21 & 5,87 & Asetilsalisilik asit & 21 & 5,48 \\
\hline Diklofenak & 10 & 2,79 & Diklofenak & 10 & 2,61 \\
\hline $\begin{array}{l}\text { 3. Yaşlılarda Kaçınılması } \\
\text { Gereken İlaç-İlaç } \\
\text { Etkileşimleri }\end{array}$ & 21 & 5,87 & & 46 & 12,01 \\
\hline \multicolumn{6}{|c|}{ En sık uygunsuzluk saptanan ilaçlar } \\
\hline Ketiapin & 6 & 1,68 & Ketiapin & 7 & 1,83 \\
\hline Olanzapin & 3 & 0,84 & Olanzapin & 5 & 1,31 \\
\hline Risperidon & 3 & 0,84 & Levetirasetam & 4 & 1,04 \\
\hline $\begin{array}{l}\text { 4. Böbrek Fonksiyonlarına } \\
\text { Göre Kaçınılması ya da Doz } \\
\text { Azaltılması Gereken İlaçlar }\end{array}$ & 31 & 8,66 & & 31 & 8,09 \\
\hline \multicolumn{6}{|c|}{ En sık uygunsuzluk saptanan ilaçlar } \\
\hline Gabapentin & 9 & 2,51 & Gabapentin & 9 & 2,35 \\
\hline Levetirasetam & 9 & 2,51 & Levetirasetam & 9 & 2,35 \\
\hline Pregabalin & 4 & 1,12 & Pregabalin & 4 & 1,04 \\
\hline Toplam* & 358 & 100,0 & & 383 & 100,0 \\
\hline
\end{tabular}

*Dört bölüme ait ana toplamlar ve yüzdeler verilmiştir. 
Tablo 4. Hastaların uygunsuz ilaç kullanım durumlarının kullandıkları ilaç sayıları ile karşılaştırılması

\begin{tabular}{|c|c|c|c|c|c|c|}
\hline \multirow{2}{*}{ UİK } & \multicolumn{3}{|c|}{ İlaç kullanımı } & \multirow{2}{*}{$\begin{array}{c}\text { Toplam } \\
\text { n(\%) }\end{array}$} & \multirow{2}{*}{$\mathbf{x}^{2}$} & \multirow{2}{*}{$\mathbf{p}$} \\
\hline & $\begin{array}{c}\text { 1-4 ilaç } \\
\text { n(\%) }\end{array}$ & $\begin{array}{c}5-9 \text { ilaç } \\
\text { n(\%) }\end{array}$ & $\begin{array}{c}10 \text { ve üstü } \\
\text { n(\%) }\end{array}$ & & & \\
\hline Yok & $65(69,89)$ & $173(56,54)$ & $41(45,05)$ & $279(56,94)$ & \multirow{2}{*}{11,626} & \multirow{2}{*}{0,003} \\
\hline Var & $28(30,11)$ & $133(43,46)$ & $50(54,95)$ & $211(43,06)$ & & \\
\hline
\end{tabular}

* Ki-kare testi

\section{Tartışma}

Evde sağlık birimimize kayıtlı hastaların polifarmasi ve potansiyel uygunsuz ilaç kullanımı açısından incelenmesini, ayrıca uygunsuz ilaç kullanımını değerlendirmek için kullanılan AGS Beers kriterlerinin 2015 ve 2019 versiyonlarının araştırma popülasyonumuzda klinik açıdan önemli bir fark oluşturup oluşturmadığının incelendiği çalışmamız bazı dikkat çekici sonuçlar ortaya koymaktadır.

Çalışmamıza dahil edilen hastaların 65 yaş ve üstü olduğu ve evde bakım hastalarının çoğunun yaşlı, düşkün hastalar olduğu düşünüldüğünde yaş ortalamasının yüksek olması ve hastaların \%49,5'inin 85 yaş ve üzerinde olması beklenen bir durumdur. Hastaların cinsiyet dağılımlarına bakıldığında büyük çoğunluğu kadınların oluşturduğu görülmektedir (kadın/erkek oranı:2,57). Öztürk ve arkadaşlarının evde sağlık birimine kayıtlı hastaların sosyodemografik özelliklerini inceledikleri çalışmada; kadın hastalar 716 (\%64,8) kişi iken, tüm hastaların yaş ortalaması 78,24 15,43 yıl, yaş gruplarına göre 85 yaș ve üstü hastalar \%40,5 (n=448) saptanmıştır. ${ }^{14}$ Çalışmamızdaki demografik verilerin literatürdeki verilerle benzer olduğu görülmüştür.

ICD-10'a göre hastaların aldıkları tanılar sıklık sırasına göre incelendiğinde; hipertansiyon, yaygın anksiyete bozukluğu, diabetes mellitus, Alzheimer, aterosklerotik kalp hastalığı göze çarpmaktadır. Arıcı ve arkadaşlarının yapmış oldukları Türk Hipertansiyon Prevalans Çalışması'na göre; geriatrik popülasyonda ( $\geq$ 65 yaş) hipertansiyon prevalansı \%75,1 (erkeklerde \%67,2, kadınlarda \%81,7) olup çalıșmamızla benzer olduğu görülmüştür. ${ }^{15}$ İkinci sıklıkta yaygın anksiyete bozukluğu tanısının olması, 65 yaş ve üstü hastalarda kronik hastalıkların artmasıyla birlikte anksiyetenin de arttığını göstermektedir. Karahan ve arkadaşlarının geriatrik hastalarda kronik hastalıkların ve polifarmasinin anksiyete üzerine etkisini araştırdıkları çalışmalarında; en az üç kronik hastalığı olan hastalarda geriatrik anksiyete ölçeği puanlarının artmış olduğu 
ve bu durumun yaşlılarda çok sayıda kronik hastalık varlığının sağlıkla ilgili yaşam kalitesini azaltacak düzeyde anksiyete ile birlikteliğini göstermektedir. ${ }^{16}$

Türkiye Diyabet Epidemiyolojisi (TURDEP-II) çalışmasında toplumumuzdaki genel diyabet prevalansı \%13,7 olarak saptanmıştır. ${ }^{17}$ 2015-2020 Türkiye Diyabet Programında yayınlanan verilere göre 2012 yılında ülkemizdeki 65 yaş ve üstü nüfusta diabetes mellitus prevalansı $\% 32$ oranındadır. ${ }^{18}$ Çalışmamıza dahil edilen hastalarda diabetes mellitus görülme oranının yüksek olması, hastaların 65 yaş ve üstünde olması ve evde sağlık hizmeti kapsamında olmaları ile açıklanabilir.

Polifarmasi ve aşırı polifarmasiyle ilgili faktörlerin incelendiği ve toplam 736 hastanın dahil edildiği bir çalışmada, hastaların 237'sinde $(\% 32,2)$ polifarmasi, 158 'inde $(\% 21,4)$ aşırı polifarmasi saptanmıştır. ${ }^{7}$ Herr ve arkadaşlarının 2350 hastada yapmış oldukları polifarmasinin prevalansını ve mortalite üzerine etkisini araştırdıkları çalışmalarında; \%53,6 (n=1 205) hastada polifarmasi, \%13,8 (n=311) hastada aşırı polifarmasi saptanmış olup, bulgularımızı destekler niteliktedir. ${ }^{19}$ Artan yaş ile birlikte hastalık semptomlarında artış olmasının ve her semptoma ayrı ilaç reçete edilmesinin kullanılan ilaç miktarını artırdığı düşünülmektedir. Kutsal ve arkadaşlarının yaşlılarda polifarmasiyi inceledikleri çok merkezli çalışmasında da kronik hastalık sayısı ile polifarmasi durumu arasında bizim çalışmamızdaki gibi anlamlı bir birliktelik bulunmuştur. ${ }^{20}$

Çalışmamıza dahil edilen 493 hastanın uygunsuz ilaç kullanımı durumları 2015 ve 2019 AGS Beers kriterlerine göre incelenmiştir. 2015 AGS Beers kriterlerine göre $211(\% 43,06)$ hastada toplamda 358 potansiyel UIKK durumu saptanmış olup, 2019 AGS Beers kriterlerine göre ise 211 hastada 388 potansiyel UİK durumu saptanmıştır. Uygunsuz tespit edilen ilaç kullanım durumları toplamının birbirine yakın olduğu görülmüştür. 2015 AGS Beers kriterlerinin kullanıldığı, Gutierrez-Valencia ve arkadaşlarının 200 hastanın dahil edildiği retrospektif çalışmasında; geriatrik popülasyonda UİK durumu \%71 oranında tespit edilmiştir. ${ }^{21}$ İspanya'da yapılmış olan bu çalışmanın ortaya koyduğu oranın bizim bulgularımızın hayli üzerinde olması ilgi çekicidir.

Çalışmamızda en sık potansiyel uygunsuz kullanım ketiapinde saptanmıştır. Ketiapin kullanan hastaların tanıları incelendiğinde; büyük çoğunluğunda yaygın anksiyete bozukluğu ve depresif nöbet olduğu görüldüğünden, şizofreni ve bipolar bozukluk tanıları olmayan bu hastalarda UíK durumu olarak değerlendirilmiştir. İkinci en sık UİK durumu hipertansiyon tedavisinde kullanılan periferik alfa-1 blokör olan doksazosindir. Çalışmamıza dahil edilen hastaların 65 yaş ve üstü evde bakım hastaları olduğu düşünüldüğünde bu popülasyonda hipertansiyon prevalansı yüksektir. Yaşlılarda periferik alfa-1 blokörler ilk sırada tercih edilen antihipertansifler olmamakla birlikte, çoklu antihipertansif ilaç tedavisine rağmen hedef değerlere ulaşmakta güçlük çekildiğinde kullanılmaktadır. Ayrıca benign prostat hipertrofisi gibi komorbid durumlarda dual etkilerinden yararlanmak amaciyla periferik alfa-1 blokörler tercih edilmektedir. ${ }^{22}$ Son yayınlanan kılavuzlara göre; yaşlı hastalarda evre-1 hipertansiyonu tedavi etmenin faydası olmadı̆̆ı 
belirtilmektedir. Hatta bu hastalarda tansiyonu düşürmek postural hipotansiyon ve dolayısıyla düşme riskini artırarak ek komorbiditelere sebep olabilmektedir. ${ }^{23}$ Üçüncü sıklıkta UİK durumu olarak PPİ (lansoprazol, esomeprazol, pantoprazol) kullanımı saptanmıştır. Yaşlı popülasyonda tanı almış hastalık sayısının yüksek olması polifarmasiye neden olmaktadır. Polifarmasi ile beraber en sık görülen sorun olan gastrointestinal sistem yan etkisini azaltmak için PPİ ilaçlar çok sık reçete edilmektedir. Çalışmamızda hastalarının ne kadar süredir PPİ kullandığını dosya üzerinden saptayamadığımız için yüksek riskli grup (oral kortikosteroid ve NSAİI kullanmak) dışında kalan kullanımlar UİK kabul edilmiştir. 2014 yılı Türkiye İlaç ve Tıbbi Cihaz Kurumu (TİTCK) verilerine göre birinci basamak sağlık kuruluşlarında yazılmış olan reçetelerin \%23,2'si 65 yaş üstü bireylere reçete edilmiştir. Bu reçetelerde en sık yazılan ilaçlar sırasıyla; diklofenak (\%11,9), asetilsalisilik asit $(\% 9,2)$, lansoprazol $(\% 7)$ ve pantoprazoldür $(\% 6,2) .^{24}$ Klinik pratikte birçok hastanın yeterli endikasyon olmaksızın proton pompa inhibitörü (PPI) tedavisi kullandığı görülmektedir. ${ }^{25}$

Çalışmaya dahil edilen 493 hastanın UİK durumu 2015 ve 2019 AGS Beers kriterlerine göre değerlendirilmiş olup, yapılan güncellemelerin bizim hastalarımız açısından üçüncü bölüm haricinde bir fark oluşturmadığı görülmüştür. AGS Beers kriterleri üçüncü bölümünde yaşlılarda kaçınılması gereken ilaç-ilaç etkileşimleri listelenmektedir. Bu listeye göre; düşme riskini artırdığından dolayı 3 ve daha fazla santral sinir sistemi üzerinden etkili olan ilacın kullanılmasından kaçınılması önerilmektedir. Santral sinir sistemini etkileyen ilaçlar; antipsikotikler, benzodiazepinler, benzodiazepin reseptör agonisti hipnotikler, trisiklik antidepresanlar, SSRİ ve opioidlerdir. Çalışmamızda 2015 AGS Beers kriterlerine göre bu durumu kapsayan her 3 ilaç da UİK olarak değerlendirilmiştir. Hastalarımızda 10 farklı etken madde için toplamda 21 UİK durumu saptanmıştır. Bu etken maddelerin büyük çoğunluğu antipsikotik sınıfında bulunmakta olup en sık UİK durumu ketiapinde saptanmıștır. 2019 AGS Beers kriterlerinde ise; opioid ve benzodiazepinlerin birlikte kullanımından her iki ilaç için de doz aşımı riskini artırdığı için kaçınılması önerilmiştir. Ayrıca opioidler ile gabapentin ve pregabalinin solunum depresyonu ve ölüm dahil olmak üzere ciddi sedasyona bağlı advers olay riskini artırması nedeniyle birlikte kullanımından kaçınılması önerilmektedir. Santral sinir sistemini etkileyen ilaçlar listesi; antiepileptikler, antipsikotikler, benzodiazepinler, benzodiazepin reseptör agonisti hipnotikler, trisiklik antidepresanlar, SSRİ, SNRİ ve opioidler olarak güncellenmiştir. 2019 AGS Beers kriterleri üçüncü bölümüne göre; 20 farklı etken maddede toplamda 46 UİK durumu saptanmıștır. En sık saptanan UİK durumu yine ketiapin olmuştur.

Uygunsuz ilaç kullanımına yol açan en sık nedenlerden biri de polifarmasidir. Çalışmamıza dahil edilen hastaların kullandıkları ilaç sayısı arttıkça uygunsuz ilaç kullanımı oranının da arttığı saptanmıştır. Bulgularımızı destekler şekilde, Steinman ve arkadaşlarının çalışmasında da 196 hastanın 128'inde (\%65) en az bir uygunsuz ilaç kullanımı olduğu ve kullanılan ilaç sayısı arttıkça uygunsuz ilaç kullanımı sıklığının da arttığı görülmüştür. ${ }^{26}$ Beers ve STOPP kriterleri kullanılarak komorbiditesi olan yaşlılarda uygunsuz ilaç kullanımının değerlendirildiği bir diğer çalışmada ise, her iki kritere göre de çoklu ilaç kullanımıyla uygunsuz 
ilaç kullanımının arttığı görülmüştür. ${ }^{27}$ Tüm bu bulgular ışığında, özellikle çoklu ilaç kullanımı olan hastalarda, potansiyel ilaç uygunsuzluğu açısından dikkatli olunması gerektiği söylenebilir. Yaşlı hastaları tedavi etmek kadar, tedavilerini güncel kılavuzlara göre yeniden gözden geçirmek ve kullandıkları ilaç sayılarını azaltmak da üzerinde durulması gereken bir konu haline gelmiştir.

Polifarmasi ve UİK durumunun tespit edilmesinde ve önlenmesinde birinci basamak çalışanlarının rolü önemlidir. Geriatrik popülasyonla daha sık karşılaşan ve hastaları sürekli takip altında tutabilme imkânı olan aile hekimlerinin polifarmasi ve UİK durumu hakkında bilgi ve deneyimlerini artırması büyük önem taşımaktadır. $\mathrm{Bu}$ nedenle uygunsuz ilaçların tespit edilmesinde, polifarmasinin ve ilaç-ilaç etkileşimlerinin önlenmesinde kullanılan rehberlerin klinik pratikte daha fazla kullanılmaları gerektiği düşüncesindeyiz. Sağlık hizmeti sunucuları tarafından bu rehberlerin ülkemiz standartlarına göre yeniden düzenlenmesi ve kolay ulaşılabilir hale getirilmesi başta aile hekimleri olmak üzere bütün hekimler için faydalı olacaktır.

Özetle, çalışmamızda Evde Sağlık Birimi'ne kayıtlı 65 yaş ve üstü hastaların tamamına yakınının kullandığı en az bir ilacı olduğu görülmüş olup yarısından fazlasında polifarmasi saptanmıştır. Polifarmasiyle orantılı bir şekilde hastalar arasında UİK durumu da önemli bir oranda fazla olup, polifarmasi varlığı UİK durumu sıklığını artırmaktadır. Çalışmamızda UİK durumu 2015 ve 2019 AGS Beers Kriterleri kullanılarak tespit edilmiştir. Bu iki versiyonun UİK durumunu saptama açısından hasta sayıları eşit olmasına rağmen, 2019 versiyonunda daha fazla etken maddede uygunsuzluk saptanmıştır.

\section{Kisıtlılıklar}

Evde sağlık biriminin hastalarıyla yapılan çalışmamızda sadece ev ziyaretleri sırasında güncellenebilen hasta dosyalarının kullanılmış olması çalışmamızın kısıtlılıklarındandır. Hastaların kullandıkları ilaçlar, tanılar, kişisel bilgiler ve çalışmamızda kullanılan diğer veriler, son yapılan ev ziyareti kayıtlarından alınmıştır. Dosyalara kaydedilen hastaların kullandıkları ilaçları, ziyaret sırasında hasta yakınları tarafından gösterilen ilaçlar olduğundan, bu sırada gösterilmeyen ilaçlar kaydedilmemiş olabilir. Bu durum bazı uygunsuzlukların eksik tespit edilmesine yol açmış olabilir.

Hastaların kullandıkları ilaçları, yazılan geçmiş reçetelerinden ve ilaç kullanım raporlarından kontrol edilse dahi, bazı ilaçları hangi endikasyonla kullandıklarının tam olarak anlaşılamaması ve kullanım süresinin tam olarak bilinememesi çalışmamızın bir diğer kısıtlılığıdır. Bu nedenle tespit edilen bazı uygunsuzluklar fazla ya da eksik tespit edilmiş olabilir. 


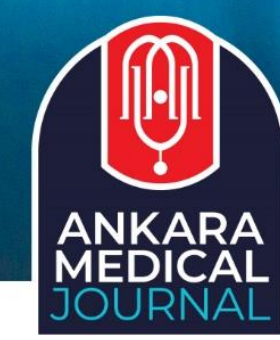

\section{Etik onay}

Çalışmamız için xxx Üniversitesi Sosyal ve Beşeri Bilimler Etik Kurulu'ndan 31.07.2019/08 onay numarasıyla izin alınmıştır.

\section{Çıkar çatışması}

Araştırmamızda herhangi bir çıkar çatışması bulunmamaktadır. Araştırma için herhangi bir maddi destek alınmamıştır. 


\section{Kaynaklar}

1. Kerry Z. Rational drug use in elderly. Ege Journal Of Medicine. 2015;54:62-73.

2. Devlet Planlama Teşkilatı. Türkiye'de Yaşlıların Durumu ve Yaşlanma Ulusal Eylem Planı. Sosyal sektörler ve koordinasyon genel müdürlüğü; 2007.

3. Azad N, Tierney M, Victor G, Kumar P, Bilodeau M. Adverse drug events in the elderly population admitted to a tertiary care hospital/practitioner application. Journal of Healthcare Management. 2002;47(5):295.

4. Hanlon JT, Lindblad CI, Hajjar ER, McCarthy TC. Update on drug-related problems in the elderly. Am J Geriatr Pharmacother. 2003;1(1):38-43. (doi:10.1016/s1543-5946(03)80014-4).

5. Hajjar ER, Cafiero AC, Hanlon JT. Polypharmacy in elderly patients. Am J Geriatr Pharmacother. 2007;5(4):345-51. (doi:10.1016/j.amjopharm.2007.12.002).

6. Turgeon J, Michaud V, Steffen L. The Dangers of Polypharmacy in Elderly Patients. JAMA Intern Med. 2017;177(10):1544. (doi:10.1001/jamainternmed.2017.4790).

7. O'Dwyer M, Peklar J, McCallion P, McCarron M, Henman MC. Factors associated with polypharmacy and excessive polypharmacy in older people with intellectual disability differ from the general population: a cross-sectional observational nationwide study. BMJ Open. 2016;6(4):e010505. (doi:10.1136/bmjopen2015-010505).

8. Say Sahin D, Özer Ö, Zubaroğlu Yanardağ M. Yaşlı Bireylerin İlaç Kullanımına İlişkin Davranışlarının SosyoDemografik Değişkenler Açısından İncelenmesi. Mehmet Akif Ersoy Üniversitesi Sağlık Bilimleri Enstitüsü Dergisi. 2018;6(1):15-25. (doi:10.24998/maeusabed.420301).

9. American Geriatrics Society Beers Criteria Update Expert Panel. American Geriatrics Society 2019 Updated AGS Beers Criteria(R) for Potentially Inappropriate Medication Use in Older Adults. J Am Geriatr Soc. 2019;67(4):674-94. (doi:10.1111/jgs.15767).

10. Bozkurt E, Parlar A, Arslan SO. Yaşlı hastalarda uygunsuz ilaç kullanımının incelenmesi ve polifarmasi varlı̆̆l. Adıyaman Üniversitesi Sağlık Bilimleri Dergisi. 2019;5(1):1254-366. (doi:10.30569.adiyamansaglik.513045). 
11. Marcum ZA, Hanlon JT. Commentary on the new American Geriatric Society Beers criteria for potentially inappropriate medication use in older adults. Am J Geriatr Pharmacother. 2012;10(2):151-9. (doi:10.1016/j.amjopharm.2012.03.002).

12. American Geriatrics Society Beers Criteria Update Expert Panel. American Geriatrics Society updated Beers Criteria for potentially inappropriate medication use in older adults. J Am Geriatr Soc. 2012;60(4):616-31. (doi:https://doi.org/10.1111/jgs.13702).

13. American Geriatrics Society Beers Criteria Update Expert Panel. American Geriatrics Society 2015 Updated Beers Criteria for Potentially Inappropriate Medication Use in Older Adults. J Am Geriatr Soc. 2015;63(11):2227-46. (doi:10.1111/jgs.13702).

14. Ozturk GZ, Toprak D. Sociodemographic Characteristics of Patients Registered with a Home Care Unit and an Evaluation of the Health Services Offered. Sisli Etfal Hastan Tip Bul. 2018;52(1):41-6. (doi:10.14744/SEMB.2017.70883).

15. Arici M, Birdane A, Guler K, ve ark. Türk Hipertansiyon Uzlaşı Raporu. Turk Kardiyol Dern Ars. 2015;43(4):402-9. (doi:10.5543/tkda.2015.16243).

16. Şanal Karahan F, Hamarta E. Geriatrik Olgularda Kronik Hastalıkların ve Polifarmasinin Ölüm Kaygısı ve Anksiyete Üzerine Etkisi. Ege Tıp Bilimleri Dergisi. 2019;2(1):8-13. (doi:10.33713/egetbd.463608).

17. Satman İ. Türkiye Diyabet Epidemiyoloji (TURDEP II) Çalışması Genel Sonuçları (20 yaş üstü). 32. Türkiye Endokrinoloji ve Metabolizma Hastalıkları Kongresi, TURDEP Paneli 2010.

18. Sağlık Bakanlığı Türkiye Halk Sağlığı Kurumu. Türkiye Diyabet Programı 2015-2020. Ankara 2014:13.

19. Herr M, Robine JM, Pinot J, Arvieu JJ, Ankri J. Polypharmacy and frailty: prevalence, relationship, and impact on mortality in a French sample of 2350 old people. Pharmacoepidemiol Drug Saf. 2015;24(6):63746. (doi:10.1002/pds.3772).

20. Gokce Kutsal Y, Barak A, Atalay A, ve ark. Polypharmacy in the elderly: a multicenter study. J Am Med Dir Assoc. 2009;10(7):486-90. (doi:10.1016/j.jamda.2009.03.018).

21. Gutiérrez-Valencia M, Izquierdo M, Malafarina V, ve ark. Impact of hospitalization in an acute geriatric unit on polypharmacy and potentially inappropriate prescriptions: A retrospective study. Geriatrics \& Gerontology International. 2017;17(12):2354-60. (doi:10.1111/ggi.13073). 
22. Türk Kardiyoloji Derneği. Ulusal Hipertansiyon Tedavi ve Takip Kılavuzu 2000; https://tkd.org.tr/kilavuz/k03/4_2c93c.htm?wbnum=1107

23. Alp Ç, Sarak T, Çifçi A, Kabalcı M. Yaşlılarda hipertansiyona yaklaşım. TURKISH JOURNAL of CLINICS and LABORATORY. 2017;10.18663/tjcl.303497. (doi:10.18663/tjcl.303497).

24. Türkiye İlaç ve Tıbbi Cihaz Kurumu. Yaşlılarda İlaç Kullanımında Güncel Sorunlar ve Çözüm Önerileri Çalıştayı. Ankara 2015.

25. Benli AR. Birinci Basamak Sağlık Hizmetlerinde Yaşlılarda Akılcı İlaç Kullanımı. Ankara Medical Journal. 2015;15(4). (doi:10.17098/amj.95506).

26. Steinman MA, Landefeld CS, Rosenthal GE, Berthenthal D, Sen S, Kaboli PJ. Polypharmacy and prescribing quality in older people. J Am Geriatr Soc. 2006;54(10):1516-23. (doi:10.1111/j.1532-5415.2006.00889.x).

27. Hudhra K, García-Caballos M, Casado-Fernandez E, Jucja B, Shabani D, Bueno-Cavanillas A. Polypharmacy and potentially inappropriate prescriptions identified by Beers and STOPP criteria in co-morbid older patients at hospital discharge. Journal of Evaluation in Clinical Practice. 2016;22(2):189-93. (doi:10.1111/jep.12452). 